\title{
Effect of flexible spacer length on the mesophase structures of main-chain/side-chain liquid crystalline polymers based on ethyl cellulose
}

\author{
Tianhui Hu, Jie Yi, Jianbo Xiao and Hailiang Zhang
}

\begin{abstract}
Main-chain/side-chain liquid crystalline polymers (MCSCLCPs) based on ethyl cellulose (AzomEC, $m=2,4,6$, where $m$ is the length of the spacer between the main chain and mesogens) were successfully synthesized by $N, N$-dicylcohexylcarbodiimide (DCC) coupling. Molecular characterizations of the resultant polymers with different spacer lengths were performed by proton nuclear magnetic resonance, Fourier transform-infrared spectroscopy and gel permeation chromatography. The phase transitions and liquid crystalline (LC) behaviors of these polymers were investigated by differential scanning calorimetry, polarized optical microscopy and wide-angle X-ray diffraction. The results indicate that spacer length has a tremendous effect on the LC behavior of the polymer. The glass transition temperatures, phase transition temperatures and the corresponding enthalpy of transitions decreased as the flexible spacer length increased. The mesophase structures of polymers consisted of a large-scale ordered lamellar structure composed of the EC main chain and a relatively small-scale ordered structure formed by azobenzene side chains. All the polymers form a similar lamellar structure on a large scale; however, the small-scale ordered structure becomes relatively disordered, that is, from crystal $(m=2)$ to smectic $B(m=4)$ to smectic $A(m=6)$ at low temperatures.
\end{abstract}

Polymer Journal (2010) 42, 752-758; doi:10.1038/pj.2010.67; published online 28 July 2010

Keywords: DCC coupling; liquid crystalline cellulose derivative; MCSCLCP; mesophase structure; spacer length

\section{INTRODUCTION}

Combined main-chain/side-chain liquid crystalline polymers (MCSCLCPs), which consist of a liquid crystalline (LC) polymer backbone and side-chain mesogenic groups, have attracted much attention because of their versatile LC phase and surprisingly broad mesophase temperature range. ${ }^{1-9}$ In the past, many MCSCLCPs have been synthesized, and the relationship between LC behavior and structural variations has been investigated. ${ }^{10-19}$ Generally, MCSCLCPs can be classified into two kinds according to the constitution of the backbone: one is of a nonrigid nature containing some flexible spacers, ${ }^{1,3,8,11,20-24}$ and the other is of a rigid nature without any flexible spacers. ${ }^{4,13,15,25,26}$ Recently, we reported novel MCSCLCPs based on mesogen-jacketed liquid crystalline polymers and ethyl cellulose (EC): these types of MCSCLCPs exhibit very interesting and versatile supramolecular structures. ${ }^{27,28}$

Cellulose, which is the main constituent of plant cell walls and is abundant in nature, is known for its excellent biocompatibility and thermal and mechanical properties. ${ }^{29-32}$ Similar to polypeptides and DNA, cellulose can form cholesteric LC phases. ${ }^{33}$ Werbowyj and Gray $^{34}$ first reported the cholesteric phase of aqueous hydroxypropyl cellulose in 1976. Since then, the LC behaviors of cellulose derivatives have aroused much interest in LC polymers within the scientific community. ${ }^{35-44}$ During the past few years, rigid mesogens have been introduced into the backbone of cellulose to investigate the LC behavior of the resultant cellulose derivatives. ${ }^{45-49}$ Although the chemical structure of these cellulose derivatives is similar to that of the combined MCSCLCPs, ${ }^{16,26}$ rigid mesogenic side groups cannot form ordered structures themselves and merely function as substitutes of cellulose derivatives; therefore, these polymers exhibit the LC behavior only of the cellulose backbone.

In a previous study, we reported the synthesis and phase behaviors of novel MCSCLCPs on the basis of EC. ${ }^{28}$ Owing to the interaction between side-chain mesogens and the backbone of cellulose, the LC behaviors and phase structures of the resulting polymers are more complex than those of conventional SCLCPs containing azobenzene mesogens or common cellulose derivatives. Moreover, transition temperatures and phase structures are found to be dependent on the degree of substitution (DS); namely, the polymer with low DS forms only cholesteric phases possessed by the cellulose backbone, but the polymer exhibits MCSCLCP properties when DS is increased to a certain degree.

Thus, we designed and synthesized samples with different spacer lengths to explore the relationship between spacer length and

Key Laboratory of Polymeric Materials \& Application Technology of Hunan Province, Key Laboratory of Advanced Functional Polymer Materials of Colleges and Universities of Hunan Province, College of Chemistry, Xiangtan University, Hunan Province, China

Correspondence: Professor H Zhang, Key Laboratory of Polymeric Materials \& Application Technology of Hunan Province, Key Laboratory of Advanced Functional Polymer Materials of Colleges and Universities of Hunan Province, College of Chemistry, Xiangtan University, Xiangtan 411105, Hunan Province, China.

E-mail: hailiangzhang@xtu.edu.cn

Received 14 March 2010; revised 6 June 2010; accepted 15 June 2010; published online 28 July 2010 
mesophase structure. In this article, we describe the synthesis and LC behavior of combined LC polymers with different spacer lengths. The molecular characterizations of the resultant polymers were performed by proton nuclear magnetic resonance $\left({ }^{1} \mathrm{H}\right.$ NMR), Fourier transforminfrared spectroscopy (FT-IR) and gel permeation chromatography (GPC). The phase transitions and LC behaviors of these polymers were investigated by differential scanning calorimetry (DSC), polarized optical microscopy (POM) and wide-angle X-ray diffraction (WAXD)

\section{EXPERIMENTAL PROCEDURE}

\section{Instruments}

${ }^{1} \mathrm{H}$ NMR spectra were recorded on a Bruker ARX $400 \mathrm{MHz}$ spectrometer (Bruker BioSpin GmbH, Rheinstetten, Germany) with tetramethylsilane as the internal standard at room temperature in chloroform $\mathrm{d}\left(\mathrm{CDCl}_{3}\right)$. FT-IR spectra in $\mathrm{KBr}$ pellets were recorded on a Perkin-Elmer Spectrum One FT-IR spectrophotometer (Perkin Elmer, Waltham, MA, USA). Elemental analysis was carried out with an Elementar Vario EL instrument (Elementar Analysensysteme GmbH, Hanau, Germany).

GPC measurements were taken on a PL-GPC120 setup (Polymer Laboratories Ltd, Church Stretton, UK) equipped with a column set consisting of two PL gel $5-\mu \mathrm{m}$ Mixed-D columns $(7.5 \times 300 \mathrm{~mm}$, effective molecular weight (MW) range $0.2-400.0 \mathrm{~kg} \mathrm{~mol}^{-1}$ ) using $N, N$-dimethylformamide that contained $0.01 \mathrm{M} \mathrm{LiBr}$ as the eluent at $80^{\circ} \mathrm{C}$ at a flow rate of $1.0 \mathrm{ml} \mathrm{min}^{-1}$. Narrowly distributed polystyrene standards in the MW range of $0.5-7500.0 \mathrm{~kg} \mathrm{~mol}^{-1}$ (PSS) were used for calibration.

The thermal transitions of the LC polymers were detected using DSC (TA-Q10). Temperature and heat flow were calibrated using standard materials (indium and zinc) at cooling and heating rates of $10^{\circ} \mathrm{C} \mathrm{min}^{-1}$. Samples with a typical mass of 3-10 $\mathrm{mg}$ were encapsulated in sealed aluminum pans.

The LC texture of the polymers was examined under POM (Leica DM-LM-P; Leica Microsystems GmbH, Wetzlar, Germany) coupled with a Mettler-Toledo hot stage (Mettler Toledo, Greifensee, Switzerland; FP82HT). Films with a thickness of $\sim 10 \mu \mathrm{m}$ were casted from $\mathrm{CHCl}_{3}$ solution and slowly dried at room temperature.

WAXD powder experiments were conducted on a Philips X'Pert Pro diffractometer (Philips, Eindhoven, Netherlands) with a 3-kW ceramic tube as the $\mathrm{X}$-ray source $(\mathrm{Cu} \mathrm{K} \alpha)$ and an X'celerator detector. The sample stage was set horizontally. The reflection peak positions were calibrated with silicon powder $\left(2 \theta>15^{\circ}\right)$ and silver behenate $\left(2 \theta<10^{\circ}\right)$. Background scattering was recorded and subtracted from the sample patterns. A temperature control unit
(Paar Physica TCU 100; Anton Paar GmbH, Graz, Austria) in conjunction with the diffractometer was used to study the structural evolution as a function of temperature.

\section{Materials}

All materials used in this study were commercial samples and were used as supplied, unless otherwise stated. EC $(\mathrm{DS}=2.32)$ was purchased from Luzhou North Chemical Industry Co Ltd. p-Methoxyaniline (Sinopharm Chemical Reagent Co. Ltd, Shanghai, China, 99\%), N,N'-dicylcohexylcarbodiimide (DCC; Sinopharm Chemical Reagent Co. Ltd, 95\%), 4-dimethylaminopyridine (Acros, Geel, Belgium, 99\%), ethyl bromoacetate (Alfa Aesar, Beijing, China, 98\%), ethyl 4-bromobutyrate (Alfa Aesar, 98\%) and ethyl 6-bromohexanoate (Alfa Aesar, 99\%) were used as received. Acetone (AR; Beijing Chemical Co., Beijing, China) was refluxed over potassium permanganate and distilled before use. Tetrahydrofuran (THF) was distilled from sodium and benzophenone. Other solvents and reagents were of AR grade and used without further purification.

\section{Synthesis of intermediates and polymers}

Scheme 1 shows the synthetic route of the intermediates and polymers.

\section{4-Hydroxy-4'-methoxy azobenzene}

4-Hydroxy-4'-methoxy azobenzene was prepared according to the method described by Stewart and Imrie. ${ }^{50}$ Thereafter, a solution of sodium nitrite $(28.9 \mathrm{~g}, 0.42 \mathrm{~mol})$ in distilled water $(150 \mathrm{ml})$ was added slowly with vigorous stirring to a solution of $p$-methoxyaniline $(50.4 \mathrm{~g}, 0.41 \mathrm{~mol})$ in $3 \mathrm{~m}$ hydrochloric acid $(500 \mathrm{ml})$ at $0{ }^{\circ} \mathrm{C}$. The resulting diazonium salt solution was then slowly added to a stirred solution of phenol $(39.4 \mathrm{~g}, 0.42 \mathrm{~mol})$ in $10 \%$ aqueous sodium hydroxide $(400 \mathrm{ml})$ at $0{ }^{\circ} \mathrm{C}$. The dark brown suspension was acidified, and the precipitate formed was filtered and washed repeatedly with water to remove any remaining reactants. The product was recrystallized from ethanol/water (1:2) and dried under vacuum. Yield: $76.2 \mathrm{~g}, 81.5 \% .{ }^{1} \mathrm{H} \mathrm{NMR}\left(400 \mathrm{MHz}, \mathrm{CDCl}_{3}\right.$, p.p.m.): 7.45 (q, 4H, $\mathrm{Ar}-\mathrm{H}), 6.95$ (q, 4H, $\mathrm{Ar}-\mathrm{H}), 3.84\left(s, 3 \mathrm{H},-\mathrm{CH}_{3}\right)$.

\section{Ethyl 6-(4-methoxybenzene-4'-yloxy) hexanoate}

Ethyl 6-bromohexanoate $(18.3 \mathrm{~g}, 0.082 \mathrm{~mol})$, 4-hydroxy-4-methoxy azobenzene $(15.0 \mathrm{~g}, 0.066 \mathrm{~mol})$ and anhydrous potassium carbonate $(38.0 \mathrm{~g}, 0.275 \mathrm{~mol})$ were stirred in acetone $(100 \mathrm{ml})$ in a flask under a nitrogen atmosphere under reflux for $48 \mathrm{~h}$. Subsequently, the solution was precipitated into cold water and collected by vacuum filtration. The crude product was purified by recrystallization from acetone and then separated through a silica gel column using $\mathrm{CH}_{2} \mathrm{Cl}_{2}$ as the eluent. The first ingredient was collected. By removing the solvent with a rotating vaporizing apparatus, the product, ethyl 6-(4-methoxybenzene-4'-yloxy)

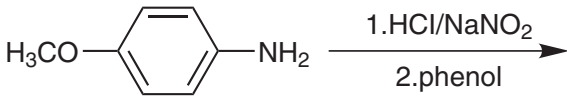<smiles>COc1ccc(N=Nc2ccc(O)cc2)cc1</smiles>

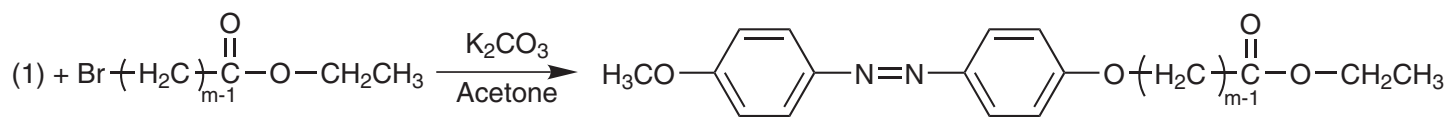

(2)

$(2$
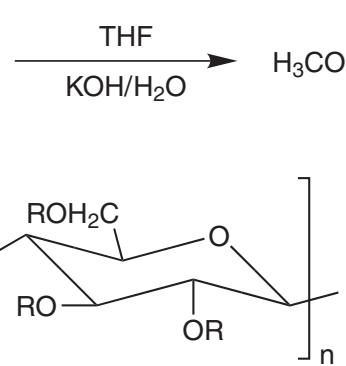

$m: 2,4,6$

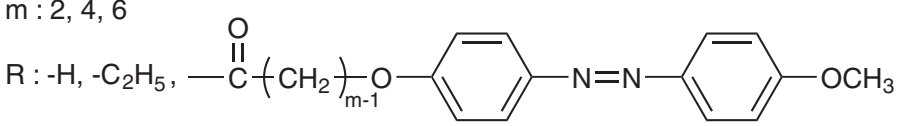

Scheme 1 The synthesis route of intermediates and polymers. 
hexanoate (M6E) (19.7g, yield: $81 \%$ ), was obtained. ${ }^{1} \mathrm{H}$ NMR $(400 \mathrm{MHz}$, $\mathrm{CDCl}_{3}$, p.p.m.): $7.90(q, 4 \mathrm{H}, \mathrm{Ar}-\mathrm{H}), 7.01(t, 4 \mathrm{H}, \mathrm{Ar}-\mathrm{H}), 4.14(q, 2 \mathrm{H}$, $\left.-\mathrm{COOCH}_{2}-\right), 4.04\left(t, 2 \mathrm{H},-\mathrm{OCH}_{2}-\right), 3.88\left(s, 3 \mathrm{H},-\mathrm{OCH}_{3}\right), 2.35(t, 2 \mathrm{H}$, $\left.-\mathrm{CH}_{2} \mathrm{COO}-\right), 1.51-1.86\left(m, 6 \mathrm{H},-\mathrm{CH}_{2}-\right), 1.26\left(t, 3 \mathrm{H},-\mathrm{CH}_{3}\right)$.

\section{6-(4-methoxyazobenzene-4'-yloxy) hexanoic acid}

M6E $(18.0 \mathrm{~g}, 0.049 \mathrm{~mol})$ and potassium hydroxide $(27.4 \mathrm{~g}, 0.490 \mathrm{~mol})$ were stirred in $200 \mathrm{ml} \mathrm{THF} / \mathrm{H}_{2} \mathrm{O}(1: 1)$ for $10 \mathrm{~h}$ under reflux in a flask under a nitrogen atmosphere. The resultant slurry was poured into water $(500 \mathrm{ml})$ and then neutralized with concentrated hydrochloric acid. The yellow precipitate was filtered off, washed with water and dried under vacuum. Recrystallization from ethanol $(700 \mathrm{ml})$ provided 6-(4-methoxyazobenzene-4' acid (M6C) as a yellow powder (14.3 g, yield: $86 \%) .{ }^{1} \mathrm{H}$ NMR $(400 \mathrm{MHz}$, $\mathrm{CDCl}_{3}$, p.p.m.): 7.87 (q, 4H, Ar-H), $6.96(q, 4 \mathrm{H}, \mathrm{Ar}-\mathrm{H}), 4.01\left(t, 2 \mathrm{H},-\mathrm{OCH}_{2}-\right)$, $3.85\left(s, 3 \mathrm{H},-\mathrm{OCH}_{3}\right), 2.39\left(t, 2 \mathrm{H},-\mathrm{CH}_{2} \mathrm{COO}-\right), 1.52-1.84\left(m, 6 \mathrm{H},-\mathrm{CH}_{2}-\right)$. Anal. calcd for $\mathrm{C}_{19} \mathrm{H}_{22} \mathrm{O}_{4} \mathrm{~N}_{2}$ : C, 66.65; N, 8.18; H, 6.48; found: $\mathrm{C}, 66.51 ; \mathrm{N}, 8.03$; H, 6.36 .

\section{2-(4-methoxyazobenzene-4'-yloxy) acetic acid}

Compound 2-(4-methoxyazobenzene- $4^{\prime}$-yloxy) acetic acid (M2C) was synthesized in a manner similar to that of M6C using ethyl bromoacetate. Yield: $85 \%$, yellow crystals. ${ }^{1} \mathrm{H}$ NMR $\left(400 \mathrm{MHz}, \mathrm{CDCl}_{3}\right.$, p.p.m.): 7.91 (q, 4H, $\left.\mathrm{Ar}-\mathrm{H}\right), 7.02$ $(q, 4 \mathrm{H}, \mathrm{Ar}-\mathrm{H}), 4.77\left(s, 2 \mathrm{H},-\mathrm{CH}_{2}-\right), 3.89\left(s, 3 \mathrm{H},-\mathrm{OCH}_{3}\right)$. Anal. calcd for $\mathrm{C}_{15} \mathrm{H}_{14} \mathrm{O}_{4} \mathrm{~N}_{2}$ : C, 62.93; N, 9.79; H, 4.93; found: $\mathrm{C}, 62.85 ; \mathrm{N}, 9.64 ; \mathrm{H}, 4.74$.

\section{4-(4-methoxyazobenzene-4-yloxy) butyric acid}

Compound 4-(4-methoxyazobenzene-4-yloxy) butyric acid (M4C) was synthesized in a manner similar to that of M6C using ethyl 4-bromobutyrate. Yield: $88 \%$, yellow crystals. ${ }^{1} \mathrm{H}$ NMR ( $400 \mathrm{MHz}, \mathrm{CDCl}_{3}$, p.p.m.): $7.88(q, 4 \mathrm{H}, \mathrm{Ar}-\mathrm{H})$, $6.99(q, 4 \mathrm{H}, \mathrm{Ar}-\mathrm{H}), 4.11\left(t, 2 \mathrm{H},-\mathrm{OCH}_{2}-\right), 3.88\left(s, 3 \mathrm{H},-\mathrm{OCH}_{3}\right), 2.63(t, 2 \mathrm{H}$, $\left.-\mathrm{CH}_{2} \mathrm{COO}-\right), 2.17\left(m, 2 \mathrm{H},-\mathrm{CH}_{2}-\right)$. Anal. calcd for $\mathrm{C}_{17} \mathrm{H}_{18} \mathrm{O}_{4} \mathrm{~N}_{2}: \mathrm{C}, 64.96 ; \mathrm{N}$, 8.91; H, 5.77; found: C, 64.63; N, 8.84; H, 5.66 .

\section{Synthesis of LC polymers}

Here, the typical synthesis procedure for AzomEC is described using Azo6EC as an example. DCC $(5.8 \mathrm{~g}, 28.0 \mathrm{mmol})$ and a small amount of 4-dimethylaminopyridine were added to the mixture of EC ( $1.0 \mathrm{~g}, 2.8 \mathrm{mmol}$ hydroxy), M6C $(9.6 \mathrm{~g}, 28.0 \mathrm{mmol})$ and anhydrous THF $(100 \mathrm{ml})$ in a $250-\mathrm{ml}$ flask cooled in an ice bath. The mixture was stirred for $10 \mathrm{~h}$ at room temperature under a nitrogen atmosphere. The reaction mixture was then poured into excess methanol; the precipitate was dissolved in THF and reprecipitated into methanol. The air-dried product was Soxhlet-extracted with methanol and dried under vacuum. The DS of the polymer was determined by ${ }^{1} \mathrm{H}$ NMR. A series of samples with different spacer lengths were prepared as shown in Table 1.

\section{RESULTS AND DISCUSSION}

Synthesis and characterization of intermediates and polymers

The synthetic route of the intermediates and polymers is shown in Scheme 1. All intermediates were successfully synthesized through similar multistep reactions following procedures detailed in the literature. ${ }^{51}$ First, 4-hydroxy-4'-methoxy azobenzene was prepared by the classic diazo reaction. ${ }^{50}$ Thereafter, the obtained 4-hydroxy4 -methoxy azobenzene was refluxed with ethyl 2-bromoacetate, ethyl 4-bromobutyrate and ethyl 6-bromohexanoate in the presence of anhydrous potassium carbonate in acetone to yield the corresponding esters. Finally, mesogens with carboxyl groups were obtained by the hydrolyzation of the corresponding ester in THF and water with potassium hydroxide. Their chemical structures were confirmed by ${ }^{1} \mathrm{H}$ NMR.

The polymers (AzomEC) were prepared through DCC coupling in THF homogeneously. The resultant polymers were characterized by ${ }^{1} \mathrm{H}$ NMR, FT-IR and GPC. Here, we use EC and Azo6EC as an example to illustrate the resulting ${ }^{1} \mathrm{H}$ NMR spectra, as shown in Figure 1. In the spectrum of Azo6EC, it is evident that the characteristic resonance peaks at 7.87, 7.00 and 3.89 p.p.m. are ascribed to the aromatic hydrogens, the methoxy group and the methylene of the side groups, respectively, which shows that the azobenzene mesogens were successfully grafted to the EC backbone. The DS, defined as the average number of azobenzene mesogens attached to the anhydroglucose unit, can be estimated from the respective ${ }^{1} \mathrm{H}$ NMR spectra using DS $=1.74 I_{1} / I_{\mathrm{m}}$, where $I_{1}$ represents the integrated area of aromatic hydrogen signal at 7.87 p.p.m., and $I_{\mathrm{m}}$ denotes the area of the methyl groups of EC at 1.17 p.p.m. (see Figure 1). ${ }^{52}$ The results are listed in Table 1.

FT-IR spectroscopic analysis was performed to further confirm the structure of the resultant polymers. As shown in Figure 2, the bands at

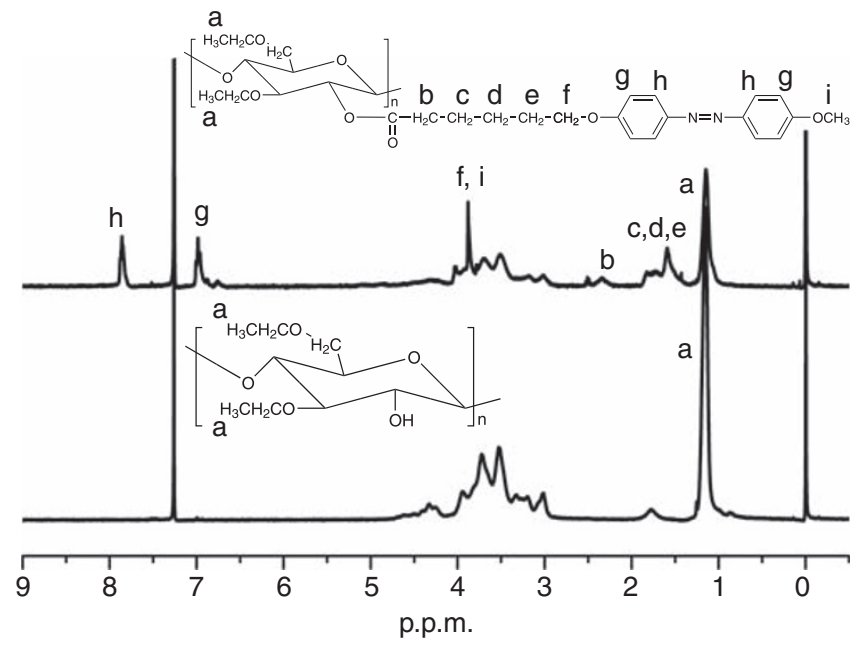

Figure $1{ }^{1} \mathrm{H}$ NMR spectra of Azo6EC and $\mathrm{EC}$ in $\mathrm{CDCl}_{3}$.

Table 1 GPC, DSC results and thermotropic properties of AzomEC

\begin{tabular}{|c|c|c|c|c|c|}
\hline Sample & Molar feed ratio & $\mathrm{M} n\left(\times 10^{-4}\right)^{\mathrm{b}}$ & $\mathrm{M} w \mathrm{MM} n^{\mathrm{b}}$ & $D S^{c}$ & Phase transitions $(\mathrm{C})$ and corresponding enthalpy changes under Cooling $\left(\mathrm{Jg}^{-1}\right)^{\mathrm{d}}$ \\
\hline $\mathrm{EC}$ & - & 3.78 & 1.56 & - & G $132 N^{*} 180(2.4)$ Iso \\
\hline Azo2EC & $1: 10$ & 6.37 & 1.41 & 0.38 & G $117 \mathrm{~K}_{1} 178(1.2) \mathrm{K}_{2} 293$ (8.3) Iso \\
\hline Azo4EC & $1: 10$ & 6.73 & 1.38 & 0.33 & G 104 SmB 161 (0.7) SmA 213 (2.4) Iso \\
\hline Azo6EC & $1: 10$ & 6.51 & 1.45 & 0.43 & G 76 SmA 134 (0.6) lamellar 183 (1.8) Iso \\
\hline
\end{tabular}

Abbreviations: DSC, differential scanning calorimetry; DS, degree of substitution; G, glass state; GPC, gel permeation chromatography; ${ }^{1} \mathrm{H}$ NMR, proton nuclear magnetic resonance; Iso, isotropic phase; K1, K2, different crystal phase; lamellar, lamellar structure; $N^{*}$, cholesteric phase; SmB, smectic B; SmA, smectic A.

aThe molar feed ratio of the hydroxy of ethyl cellulose to mesogen.

bobtained from PL-GPC120 instrument, linear PS as standards.

CDS was determined by ${ }^{1} \mathrm{H}$ NMR.

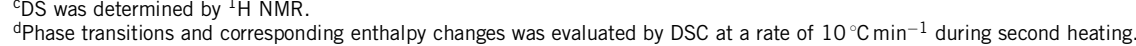




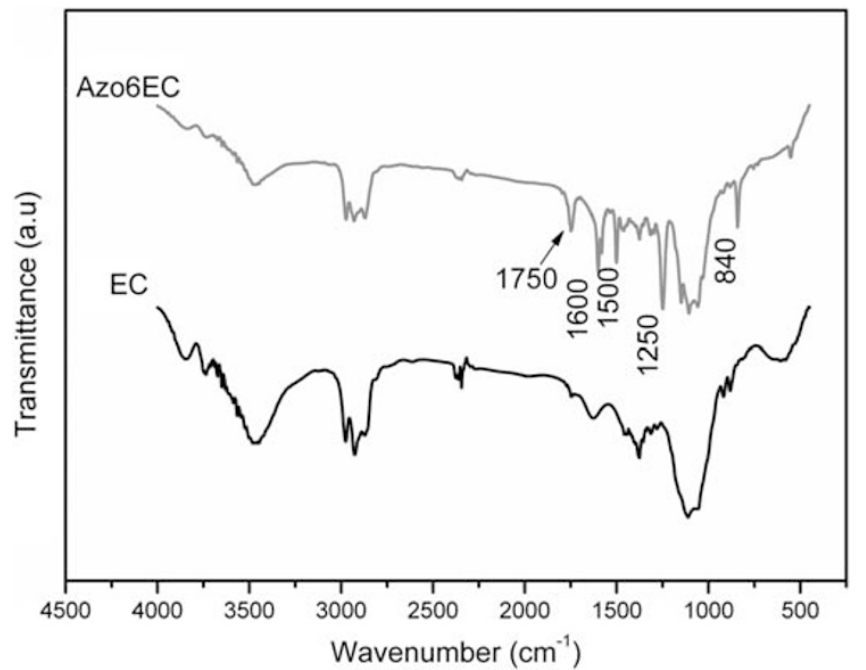

Figure 2 FT-IR spectra of EC and Azo6EC.

1600 and $1500 \mathrm{~cm}^{-1}$ in the spectrum of Azo6EC are assigned to $\mathrm{C}=\mathrm{C}$ stretching of the aromatic rings, and the peaks at 1250 and $840 \mathrm{~cm}^{-1}$ in the fingerprint region are assigned to the azobenzene mesogens. Furthermore, the characteristic peak at about $1750 \mathrm{~cm}^{-1}$ due to the $\mathrm{C}=\mathrm{O}$ vibration indicates that Azo6EC was successfully synthesized. The broad peak at about $3500 \mathrm{~cm}^{-1}$ in the spectra is attributed to the residual hydroxyl of the anhydroglucose unit of EC. These results are consistent with ${ }^{1} \mathrm{H}$ NMR spectra. The spectra of Azo2EC and Azo4EC were similar to Azo6EC; hence, they are omitted here.

The apparent MWs and MW distributions of polymers were determined by GPC analysis. The results are shown in Table 1. After grafting the mesogens to EC, an increase in MW compared with EC was found because of a change in hydrodynamic volume. By repeated precipitation and Soxhlet extraction for further purification, the MW distribution became narrower than EC. This result further confirmed the successful synthesis of AzomEC.

\section{Phase transition and LC behavior}

DSC was used to determine phase transitions and their associated enthalpy. All transition temperatures of the polymers were determined from second heating curves with a scanning rate of $10^{\circ} \mathrm{Cmin}^{-1}$. As shown in Figure 3, each sample has one glass transition and two obvious endothermic peaks. The glass transition temperatures $\left(T_{\mathrm{g}}\right)$ of the polymers gradually decreased as the flexible spacer length increased from 2 to 6 , which is ascribed to internal plasticization. ${ }^{53,54}$ Meanwhile, the temperature of the two transition peaks and the enthalpy of the corresponding transition significantly decreased with increasing spacer length, which has been attributed to the decoupling of mesogens from the backbone by flexible spacers. ${ }^{53,54}$ One may speculate that the transition at a low temperature could be attributed to a transition from a high-order to a low-order structure of sidechain mesogen packing in the LC state; for the transition at high temperatures, it is thought that the polymer is subjected to a transition from the LC structure formed by EC and azobenzene to the isotropic state. $^{19,27,28}$ All assumptions are confirmed by other experiments described below. The data related to the transitions are listed in Table 1.

The birefringence of all polymers was observed under POM, with the samples cast from chloroform solution and slowly dried at room temperature. All polymers exhibited two kinds of textures with

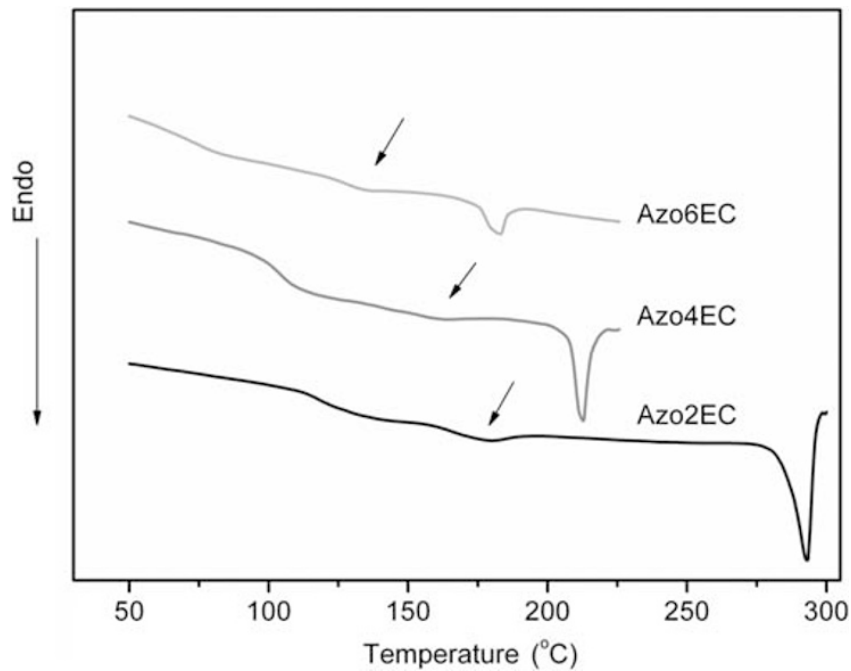

Figure 3 DSC thermograms of AzomEC during the second heating.

different colors at different temperatures, indicating two unambiguous LC phases before the isotropic state. ${ }^{28}$ These results illustrate that the POM observations are in good agreement with the DSC results. In Figure 4, the POM photographs of Azo6EC are shown as an example.

Although the DSC and POM experiments provided very valuable information about the phase transition of these LC cellulose derivatives, they could not elucidate the concrete structural evolution. To illustrate the phase structures clearly, WAXD experiments were carried out to identify the corresponding structural evolutions. Figure 5 shows the change of the structurally sensitive WAXD patterns of AzomEC at different temperatures.

Figure 5a shows the diffraction patterns of Azo2EC at 160 and $200{ }^{\circ} \mathrm{C}$. It is evident that there are two substructures in the mesophase structure: one in the low-angle region and the other in the high-angle region. Interestingly, it could be observed that the sharp Bragg reflections at $2.86^{\circ}, 8.58^{\circ}$ and $14.49^{\circ}(d=3.09 \mathrm{~nm}, 1.03 \mathrm{~nm}$ and $0.61 \mathrm{~nm}$ ) follow a ratio of 1:3:5, indicating that the lamellar structure was formed because of the microphase segregation between the EC main-chain and side-chain mesogens. However, the second- and fourth-order diffraction of the smectic layer shows that, within the smectic structure, the electron density in the center of the sublayer formed by the side chains is very close to that of the main-chain sublayer. ${ }^{55,56}$ These reflections maintain almost the same position with increasing temperature, implying that the lamellar structure still exists before the isotropic phase. Meanwhile, as shown in Figure 5a, several peaks are observed in the high-angle region, indicating that the typical crystal is formed by azobenzene mesogens, and these reflections exhibit obvious transitions with increasing temperature, demonstrating that the transition at low temperatures is the transformation of the polymorphism.

The diffraction patterns of Azo4EC are shown in Figure 5b. As reported in our previous paper, ${ }^{28}$ the structure of Azo4EC consisted of a large-scale ordered lamellar structure constructed by EC main chains and relatively small-scale ordered structures formed by azobenzene moieties. The transition at low temperatures is the transition from high-order smectic B to the low-order packing of smectic A of azobenzene mesogens.

Figure $5 \mathrm{c}$ shows the diffraction patterns of Azo6EC at 100, 160 and $200^{\circ} \mathrm{C}$. It is obvious that the mesophase structure of Azo6EC also has two substructures similar to that of Azo2EC and Azo4EC. It can be 

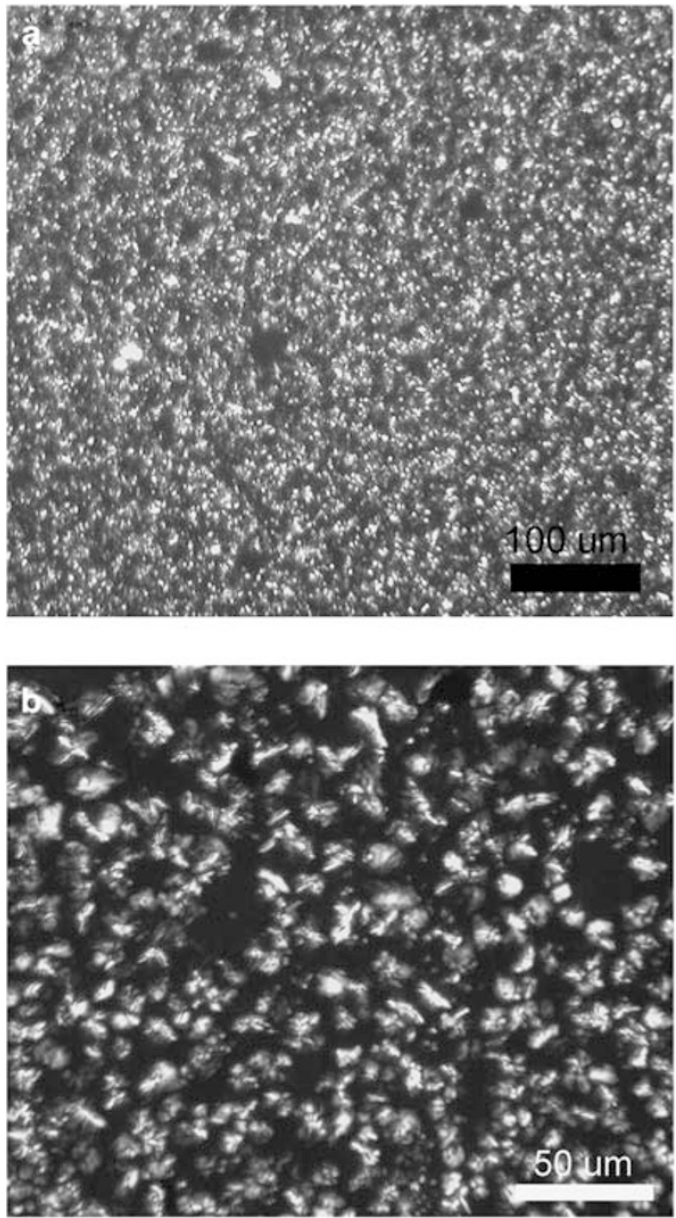

Figure 4 Representative polarized optical microscope image of the texture of Azo6EC (a, Azo6EC $100^{\circ} \mathrm{C}$; b, Azo6EC $160^{\circ} \mathrm{C}$ ).

observed that the sharp Bragg reflections at 2.17, 4.35, 6.55, 8.67 and $10.9^{\circ}(d=4.07,2.03,1.35,1.02$ and $0.81 \mathrm{~nm})$ follow a ratio of 1:2:3:4:5, showing the formation of the lamellar structure. These reflections maintain almost the same position with increasing temperature before the isotropic state, implying that the lamellar structure still exists. At the same time, the reflections in the high-angle region exhibit obvious transitions in different temperature regions. At low temperatures, a scattering halo around $2 \theta=20^{\circ}(0.44 \mathrm{~nm})$ appeared; this halo is associated with the values reported so far for the smectic A phase of azobenzene mesogens. ${ }^{57}$ As the temperature increased, this scattering halo shifted to low angle and became more diffuse, indicating that the smectic A formed by azobenzene turned into the isotropic state. Here, the transition at low temperatures is assigned as the transition from smectic A to the isotropic state of side-chain mesogens. The diffraction pattern of the isotropic state recorded at $200{ }^{\circ} \mathrm{C}$ is also shown in Figure $5 c$.

It is evident that all AzomEC $(m=2,4,6)$ polymers possess the typical combined LC behavior, ascribed to the interactions between the rod-like EC backbone and the side groups. The mesophase structure of the polymers consists of a large-scale ordered lamellar structure composed of EC main chains and a relatively small-scale ordered structure formed by azobenzene side chains. All the polymers form a similar lamellar structure at the large scale; however, it is particularly surprising to find that with an increasing number of methylene units in the side chains, the small-scale ordered structure
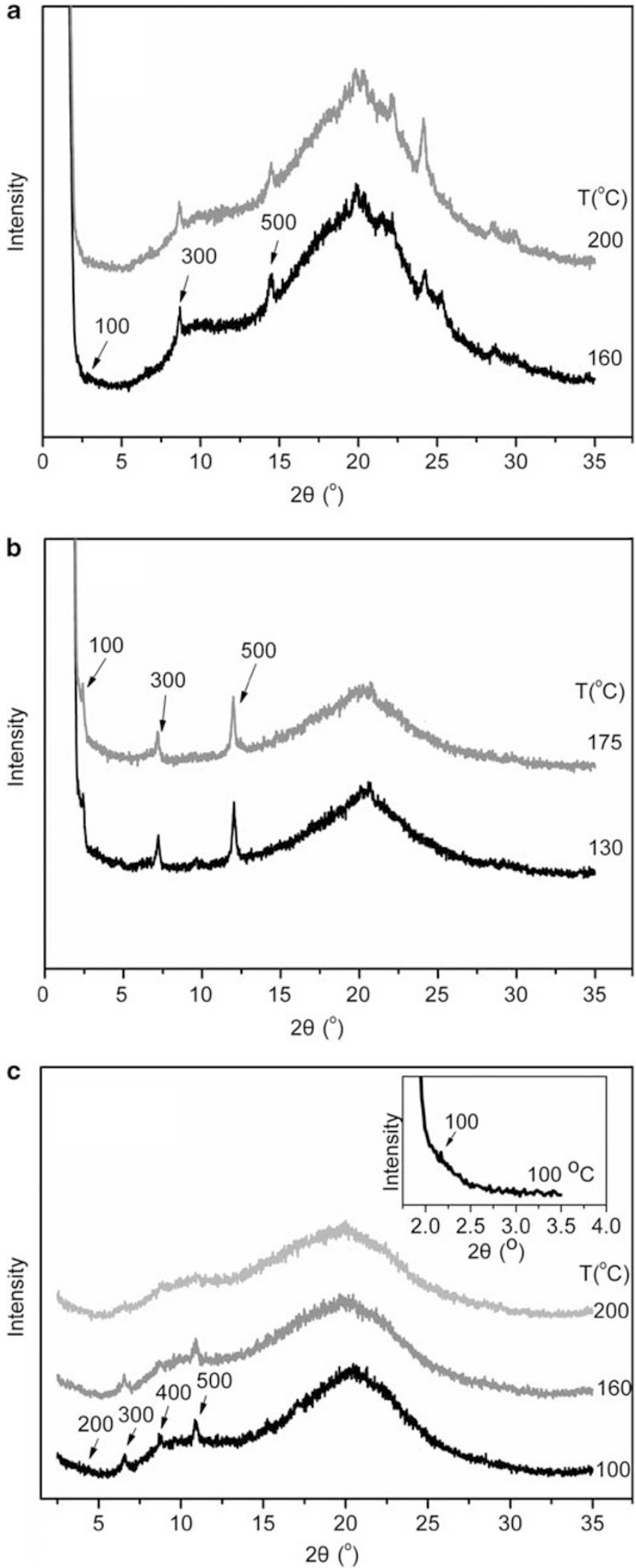

Figure 5 Sets of WAXD powder patterns of Azo2EC (a), Azo4EC (b) and Azo6EC (c) obtained during the second heating process.

becomes relatively disordered, that is, from crystal $(m=2)$ to smectic B $(m=4)$ to smectic $\mathrm{A}(m=6)$ at low temperatures. This trend may reflect the fact that the mesophase structure at the small scale is 


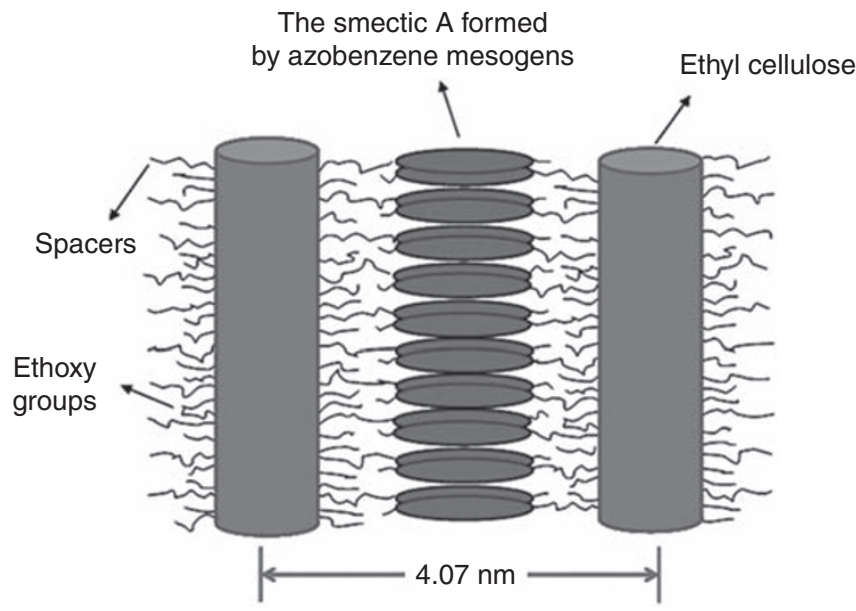

Figure 6 Schematic drawing of the mesophase structure of Azo6EC at low temperatures.

critically associated with the shapes of the individual chains, and the increasing number of methylene units gives rise to irregularities in the structure because of the asymmetrical substitution of mesogens. ${ }^{4,17}$ On the basis of the experimental data from WAXD and the size of the molecules, a possible schematic drawing of the mesophase structure of Azo6EC is illustrated in Figure 6.

\section{CONCLUSION}

We successfully synthesized a series of combined LC polymers on the basis of EC with different spacer lengths. The molecular characterizations of the resultant polymers were performed by ${ }^{1} \mathrm{H}$ NMR, FT-IR and GPC. The phase transitions and LC behaviors of these polymers were investigated by DSC, POM and WAXD. The results showed that the spacer length had a tremendous effect on the mesophase structure of the polymers. The mesophase structures of the polymers consisted of a large-scale ordered lamellar structure constructed by EC main chains and a relatively small-scale ordered structure formed by azobenzene side chains. All polymers formed a similar lamellar structure on a large scale; however, the small-scale ordered structure became disordered as the spacer length increased, that is, from crystal $(m=2)$ to smectic $\mathrm{B}(m=4)$ to smectic $\mathrm{A}(m=6)$ at low temperatures. This increasing disorder is ascribed to the fact that the increasing number of methylene units gives rise to irregularities in the structure because of the asymmetrical substitution of mesogens.

\section{ACKNOWLEDGEMENTS}

This research was financially supported by the National Nature Science Foundation of China (20874082), the Scientific Research Fund of Hunan Provincial Education Department (06A068) and the Key Project of Chinese Ministry of Education for Science and Technology (207075).

1 Reck, B. \& Ringsdorf, H. Combined liquid crystalline polymers: mesogens in the main chain and as side groups. Macromol. Rapid Commun. 6, 291-299 (1985).

2 Reck, B. \& Ringsdorf, H. Combined liquid-crystalline polymers: rigid rod and semiflexible main chain polyesters with lateral mesogenic groups. Macromol. Rapid Com mun. 7, 389-396 (1986).

3 Kremer, F., Vallerien, S. U., Zentel, R. \& Kapitza, H. Broad-band dielectric spectroscopy on a set of combined main-chain side-group liquid-crystalline polymers. Macromolecules 22, 4040-4045 (1989).

4 Piao, X. L., Kim, J.- S., Yun, Y.- K., Jin, J.- I. \& Hong, S.- K. Combined type liquid crystalline polymers composed of poly(p-phenylene terephthalate) main chain and azobenzene mesogenic side groups attached through polymethylene spacers. Macromolecules 30, 2294-2299 (1997).

5 Voigt-Martin, I. G., Durst, H., Reck, B. \& Ringsdorf, H. Structure analysis of a combined main-chain/side-group liquid crystalline polymer by electron microscopy. Macromolecules 21, 1620-1626 (1988).

6 Zentel, R. \& Reckert, G. Liquid crystalline elastomers based on liquid crystalline side group, main chain and combined polymers. Macromol. Chem. Phys. 187, 1915-1926 (1986).

7 Zentel, R., Reckert, G., Bualek, S. \& Kapitza, H. Liquid-crystalline elastomers with cholesteric and chiral smectic $C^{*}$ phases. Macromol. Chem. Phys. 190, 2869-2884 (1989).

8 Zentel, R. \& Brehmer, M. Combined LC main chain/side chain polymers. Acta Polym. 47, 141-149 (1996)

9 Endres, B. W., Ebert, M., Wendorff, J. H., Reck, B. \& Ringsdorf, H. Combined main chain/side chain polymers. A new class of liquid crystalline polymers with unusual structural, thermodynamic and dynamic properties. Liq. Cryst. 7, 217-239 (1990).

10 Reck, B., Ringsdorf, H., Gardner, K. \& Howard, S. Jr. Combined liquid-crystalline polymers: rigid-rod type main-chain polyester with lateral mesogenic groups. Macromol. Chem. Phys. 190, 2511-2526 (1989).

11 Kapitza, H. \& Zentel, R. Chiral liquid-crystalline polymers by polymer-analogous reactions. Macromol. Chem. Phys. 192, 1859-1872 (1991).

12 Pakula, T. \& Zentel, R. Mechanical behaviour of liquid-crystalline polymers and their networks. Macromol. Chem. Phys. 192, 2401-2410 (1991).

13 Ge, J. J., Zhang, A., McCreight, K. W., Ho, R.- M., Wang, S.- Y., Jin, X., Harris, F. W. \& Cheng, S. Z. D. Phase structures, transition behaviors, and surface alignment in polymers containing rigid-rodlike backbones with flexible side chains. 1. Monotropic phase behavior in a main-chain/side-chain liquid crystalline polyester. Macromolecules 30, 6498-6506 (1997).

14 Diele, S., Naumann, M., Kuschel, F., Reck, B. \& Ringsdorf, H. X-ray investigation of combined main-chain/side-chain liquid-crystalline polymers. Liq. Cryst. 7, 721-729 (1990).

15 Ruan, J., Ge, J. J., Zhang, A., Shi, J., Wang, S.- Y., Harris, F. W. \& Cheng, S. Z. D. Polymorphous structures and their phase relationships in a main-chain/side-chain liquid crystalline polyester. Macromolecules 35, 736-745 (2002).

16 Chen, B.- Q., Kameyama, A. \& Nishikubo, T. New combined liquid crystalline polymers from polyaddition of biphenol diglycidyl ether and trimeric esters. Macromolecules $\mathbf{3 2}$, 6485-6492 (1999).

17 Ruan, J.- J., Jin, S., Ge, J. J., Jeong, K.- U., Graham, M. J., Zhang, D., Harris, F. W., Lotz, B. \& Cheng, S. Z. D. Side chain length dependence on supra-molecular structures in a series of aromatic polyimides having terminal 4-cyanobiphenyl liquid crystalline side chains. Polymer 47, 4182-4193 (2006).

18 Schaefer, K. E., Keller, P. \& Deming, T. J. Thermotropic polypeptides bearing side-on mesogens. Macromolecules 39, 19-22 (2006).

19 Watanabe, J. \& Tominaga, T. Thermotropic liquid crystals in polypeptides with mesogenic side chains. 1. Macromolecules 26, 4032-4036 (1993).

20 Kapitza, H. \& Zentel, R. Combined liquid-crystalline polymers with chiral phases, 2. Lateral substituents. Macromol. Chem. Phys. 189, 1793-1807 (1988).

21 Zhou, M. \& Han, C. D. Synthesis and characterization of a combined main-chain/sidechain liquid-crystalline polymer exhibiting both thermotropic and lyotropic characteristics and its lyotropic phase behavior. Macromolecules 38, 9602-9609 (2005).

22 Huang, W. \& Han, C. D. Synthesis of combined main-chain/side-chain liquid-crystalline polymers via self-assembly. Macromolecules 39, 4735-4745 (2006).

23 Joo, S.- H., Yun, Y.- K., Jin, J.- I., Kim, D.- C. \& Zin, W.- C. Synthesis of liquid crystalline polyesters of various types by acyclic diene metathesis polymerization. Macromolecules 33, 6704-6712 (2000).

24 Poths, H., Zentel, R., Vallerien, S. U. \& Kremer, F. LC-polymers with axial chirality. Mol. Cryst. Liq. Cryst. 203, 101-111 (1991).

25 Lee, J.- W., Jin, J.- I., Jo, B.- W., Kim, J.- S., Zin, W.- C. \& Kang, Y.- S. Synthesis and properties of combined type liquid crystalline polymers - aromatic polyesters bearing biphenylazophenyl mesogenic pendants connected to the backbone through polymethylene spacers. Acta Polym. 50, 399-407 (1999).

26 Cha, S. W., Jin, J.- I., Kim, D.- C. \& Zin, W.- C. Combined type liquid crystalline poly(oxy-1,4-phenyleneoxyterephthaloyl)s bearing cholesterol pendants attached through polymethylene spacers. Macromolecules 34, 5342-5348 (2001).

27 Xie, H. L., Hu, T. H., Zhang, X. F., Zhang, H. L., Chen, E. Q. \& Zhou, Q. F. Design, synthesis, and characterization of a combined main-chain/side-chain liquid crystalline polymer based on mesogen-jacketed liquid crystal polymer via atom transfer radical polymerization. J. Polym. Sci. A Polym. Chem. 46, 7310-7320 (2008).

$28 \mathrm{Hu}$, T. H., Xie, H. L., Xiao, J. B., Zhang, H. L. \& Chen, E. Q. Design, synthesis, and characterization of a combined main-chain/side-chain liquid crystalline polymer based on ethyl cellulose. Cellulose 17, 547-558 (2010).

29 Klemm, D., Heublein, B., Fink, H.- P. \& Bohn, A. Cellulose: fascinating biopolymer and sustainable raw material. Angew. Chem. Int. Ed. 44, 3358-3393 (2005).

30 Canejo, J. P., Borges, J. P., Godinho, M. H., Brogueira, P., Teixeira, P. I. C. \& Terentjev, E. M. Helical twisting of electrospun liquid crystalline cellulose micro- and nanofibers. Adv. Mater. 20, 4821-4825 (2008).

31 Yagi, S., Kasuya, N. \& Fukuda, K. Synthesis and characterization of cellulose- $b$ polystyrene. Poly. J 42, 342-348 (2010).

32 Chang, F., Yamabuki, K., Onimura, K. \& Oishi, T. Modification of cellulose by using atom transfer radical polymerization and ring-opening polymerization. Poly. J. 40, 1170-1179 (2008). 
33 Chanzy, H., Nawrot, S., Peguy, A., Smith, P. \& Chevalier, J. Phase behavior of the quasiternary system $\mathrm{N}$-methylmorpholine- $\mathrm{N}$-oxide, water, and cellulose. J. Polym. Sci. B Polym. Phys. 20, 1909-1924 (1982).

34 Werbowyj, R. S. \& Gray, D. G. Liquid crystalline structure in aqueous hydroxypropyl cellulose solutions. Mol. Cryst. Liq. Cryst. 34, 97-103 (1976).

35 Isogai, A., Ishizu, A. \& Nakano, J. Preparation of tri-O-benzylcellulose by the use of nonaqueous cellulose solvents. J. Appl. Polym. Sci. 29, 2097-2109 (1984).

36 Bhadani, S. N. \& Gray, D. G. Cellulose-based liquid crystalline polymers; esters of (hydroxypropyl) cellulose. Mol. Cryst. Liq. Cryst. 99, 29-38 (1983).

37 Pawlowski, W. P., Sankar, S. S., Gilbert, R. D. \& Fornes, R. E. Synthesis and solid state ${ }^{13}$ C-NMR studies of some cellulose derivatives. J. Polym. Sci. A Polym. Chem. 25, 3355-3362 (1987).

38 Yamagishi, T., Fukuda, T., Miyamoto, T. \& Watanabe, J. Thermotropic cellulose derivatives with flexible substituents. Polym. Bull. 20, 373-377 (1988)

39 Jiang, S. H. \& Huang, Y. Formation and textures of ethyl-cyanoethyl cellulose/acrylic acid mesophase. J. Appl. Polym. Sci. 50, 607-613 (1993).

40 Chen, J. N., Huang, Y. F., Yuan, J. Y., Yan, S. Q. \& Ye, H. Thermotropic liquid crystalline behaviors of ethylcellulose. J. Appl. Polym. Sci. 45, 2153-2158 (1992).

41 Huang, B., Ge, J. J., Li, Y. \& Hou, H. Aliphatic acid esters of (2-hydroxypropyl) cellulose - effect of side chain length on properties of cholesteric liquid crystals. Polymer 48, 264-269 (2007).

42 Shaikh, V. A. E., Maldar, N. N., Lonikar, S. V., Rajan, C. R. \& Ponrathnam, S. Thermotropic liquid crystalline behavior of cholesterol-linked hydroxyethyl cellulose. J. Appl. Polym. Sci. 72, 763-770 (1999).

43 Rusig, I., Godinho, M. H., Varichon, L., Sixou, P., Dedier, J., Filliatre, C. \& Martins, A. F. Optical properties of cholesteric (2-hydroxypropyl) cellulose (HPC) esters. J. Polym. Sci. B Polym. Phys. 32, 1907-1914 (1994).

44 Chiba, R., Ito, M. \& Nishio, Y. Addition effects of imidazolium salts on mesophase structure and optical properties of concentrated hydroxypropyl cellulose aqueous solutions. Poly. J. 42, 232-241 (2010).
45 Terbojevich, M., Cosani, A., Focher, B., Gastaldi, G., Wu, W., Marsano, E. \& Conio, G. Solution properties and mesophase formation of 4-phenyl-benzoylcellulose. Cellulose 6, 71-87 (1999).

46 Wu, C., Huang, Y. \& Chen, S. The synthesis and thermotropic liquid crystalline behavior of mesogenic moiety-linked ethyl cellulose. Polym. Bull. 48, 33-41 (2002).

$47 \mathrm{Wu}, \mathrm{C} ., \mathrm{Gu}, \mathrm{Q}$., Huang, Y. \& Chen, S. The synthesis and thermotropic behaviour of an ethyl cellulose derivative containing azobenzene-based mesogenic moieties. Liq. Cryst. 30, 733-737 (2003)

$48 \mathrm{Wu}, \mathrm{C} ., \mathrm{Gu}, \mathrm{Q}$., Zhang, R., Huang, Y. \& Chen, S. Synthesis and Iyotropic behavior of mesogen-linked cellulose acetates. J. Appl. Polym. Sci. 92, 2693-2697 (2004).

49 Granström, M., Havimo, M., Heikkilä, M. \& Kilpeläinen, I. Synthesis, characterisation and application of novel self-assembled comb-like liquid crystalline biphenyl-cellulose as UV absorber for paper. J. Mater. Chem. 19, 639-644 (2009).

50 Stewart, D. \& Imrie, C. T. Synthesis and characterization of spin-labelled and spinprobed side-chain liquid crystal polymers. Polymer 37, 3419-3425 (1996).

51 Cormack, P. A. G., Moore, B. D. \& Sherrington, D. C. Monodisperse liquid crystalline peptides. J. Mater. Chem. 7, 1977-1983 (1997).

52 Ritcey, A. M., Holme, K. R. \& Gray, D. G. Cholesteric properties of cellulose acetate and triacetate in trifluoroacetic acid. Macromolecules 21, 2914-2917 (1988).

53 Pugh, C. \& Kiste, A. L. Molecular engineering of side-chain liquid crystalline polymers by living polymerizations. Prog. Polym. Sci. 22, 601-691 (1997).

54 Ahn, S. K., Le, L. T. N. \& Kasi, R. M. Synthesis and characterization of side-chain liquid crystalline polymers bearing cholesterol mesogen. J. Polym. Sci. A Polym. Chem. 47, 2690-2701 (2009).

55 Zhu, X. Q., Liu, J. H., Liu, Y. X. \& Chen, E. Q. Molecular packing and phase transitions of side-chain liquid crystalline polymethacrylates based on $\mathrm{p}$-methoxyazobenzene. Polymer 49, 3103-3110 (2008).

56 Xie, H. L., Liu Y, X., Zhong, G. Q., Zhang, H. L., Chen, E. Q. \& Zhou, Q. F. Design, synthesis, and multiple hierarchical ordering of a novel side-chain liquid crystalline-rod diblock copolymer. Macromolecules 42, 8774-8780 (2009).

57 Gray, G. W. \& Goodby, J. W. Smectic Liquid Crystals. (Blackie Press, Glasgow London, 1984). 